\title{
Make or buy strategy decision making in supply quality chain
}

\author{
Seyed Mohammad Seyedhosseini", Faezeh Mohammadipour, and Milad Gorji Ashtiani
}

Department of Industrial engineering, Iran University of Science \& Technology, Tehran, Iran

\begin{tabular}{|c|c|}
\hline A R T I C L E I N F O & AB S T R A C T \\
\hline $\begin{array}{l}\text { Article history: } \\
\text { Received } 20 \text { October } 2011 \\
\text { Accepted December, } 52011 \\
\text { Available online } \\
\text { 14 December } 2011 \\
\text { Keywords: } \\
\text { Cost minimization } \\
\text { Supplier selection } \\
\text { Make or Buy decision } \\
\text { Outsourcing }\end{array}$ & $\begin{array}{l}\text { Minimizing the total cost is absolutely the goal of each supply chain, which is most of the time } \\
\text { pursued. In this regards, quality related costs that have significant roles are sometimes } \\
\text { neglected. Selecting suppliers, which supply relatively high quality raw materials in a lower } \\
\text { cost is considered as a strategic decision. Make or Buy decision can be also noticed in supplier } \\
\text { selection process. In this paper, the supply strategy: Make or Buy decision (SS: MOB) is } \\
\text { studied in order to find which strategy (Make or Buy) should be chosen to minimize the total } \\
\text { costs of supply chain. Therefore, two separate models are generated for each strategy and } \\
\text { several examples are solved for the respective models. Computational experiments show the } \\
\text { efficiency of the proposed models for making decision about selecting the best strategy. }\end{array}$ \\
\hline
\end{tabular}

\section{Introduction}

The primary aim of almost all supply chain management is to control goods or services. The supply chain begins with the supply of raw materials and ends with the consumption of goods or services (Yazdian \& Shahanaghi, 2011). Nowadays, one of the goals of each supply chain is to maximize the customer satisfaction, which increases supply chain effectiveness and absolutely what makes customer highly satisfied is the quality they perceive from the products or services they consume (Heikkilä, 2002). The significance of quality enhancement is proved for organizations that intend to survive in the competitive markets. Therefore, there are many programs for improving quality in all organizations, which exist in a supply chain (Robinson \& Malhotra, 2005).

Considering supplier quality is a factor, which plays an important role for injecting quality into the supply chain (Jamshidi \& Ismaeli, 2012). In this paper, selecting suppliers that supply high quality raw materials is tied with Supply Strategy: Make-or-Buy decisions (SS:MOB). SS:MOB is a strategic decision made in a supply chain about whether to provide the required raw materials from the insourcing suppliers or outsourcing ones and it is dealt with different fields of purchasing, accounting and strategic management (Mandy, 2009; Moschuris, 2008; Moses \& Åhlström, 2008). "Make" decision refers to the condition in that supply chain aims at integrating plant and supplier operations, controlling supplier quality, considering lead time, transportation, and warehousing costs. In fact, insourcing suppliers reassure the presence of having reliable and competent suppliers that can supply

* Corresponding author Tel: +98-21-73225007

E-mail: seyedhosseini@iust.ac.ir (S. M. Seyedhosseini)

(C) 2012 Growing Science Ltd. All rights reserved. doi: $10.5267 /$ j.ijiec.2011.12.005 
whenever needed. On the other hand, "Buy" decision refers to condition in that lack of insourcing dexterity can be seen, brand is too much preferred and limited production facilities and inadequate capacities are encountered (Williamson, 2008).

The key factor that is noticed a lot in MOB is cost which is also significant in SS:MOB. In other words, SS:MOB is used when cost issues are at the pick of consideration. Two quality-related cost groups are existed in supplying raw materials from different suppliers. The first group is cost of quality (COQ) and the other one is supplier quality cost considered for increasing the quality of suppliers. COQ is defined as the expenditure incurred by the producer, user and community and associated with the quality of products or services (British Standards Institution, 1991). COQ is used for insourcing supplier. Costs of quality are categorized into prevention, appraisal, and failure costs. The literature describes four categories of costs for COQ (Srivastava, 2008):

1. Prevention cost: The cost of any action taken to investigate, prevent or reduce the risk of nonconformity or defect,

2. Appraisal cost: The cost of evaluating the achievement of quality requirements like the cost of verification and control performed at any stage of the quality loop,

3. Internal failure cost: The costs arising within an organization owing to non-conformities or defects at any stage of the quality loop, such as costs of scrap, reworking, retesting, reinspection or redesign,

4. External failure cost: The cost arising after delivery to a customer/user owing to nonconformities or defects.

Supplier quality costs are those costs associated with the activities, which are done about the quality of outsourcing suppliers and they include raw material inspection cost, documentation and rejection costs of defective raw material and cost of complaint investigation (Agarwal et al., 2011).

In this paper, using insourcing or outsourcing suppliers is investigated and SS: MOB is analyzed in order to find which decision (Make/ Buy) is more economical. In fact, SS: MOB is for the first time considered in supply chain with the aim of minimizing the total cost with an attitude towards supplier quality. Therefore, if the "Make" decision is selected, COQ will be imposed to avoid the entry of defective raw materials into supply chain and if "Buy" decision is chosen, some quality related cost is afforded by the manufacturer to inspect the quality of raw materials, which are supplied by suppliers. This paper is organized as follows: In the next section, the proposed cases and their respective mathematical models are described. Section 3 contains computational experiments and result analysis. The main finding and future research avenues are existed in section 4 .

\section{Model description}

It is assumed that a medium-term planning is going to be executed in one supply chain, which consists of $m$ manufacturing plants in which a special product (or a group of similar products) is produced. It is also assumed that the product has been composed of $f$ raw materials, which are supplied by $s$ potential suppliers of whom only $\rho$ ones will be chosen. The products are produced in plants and then kept in the warehouses inside the plants. Then the products are shipped from the plants to the customers. In addition, those numbers of products, which are remained and not transferred to the customers are kept in the plant warehouses for meeting customer demands in the next periods. The number of customers who receive the product equals $n$ and their demands are also assumed definite in all periods. Therefore, two-echelon supply chain has been noticed in this paper and is observed at Fig. 1. 


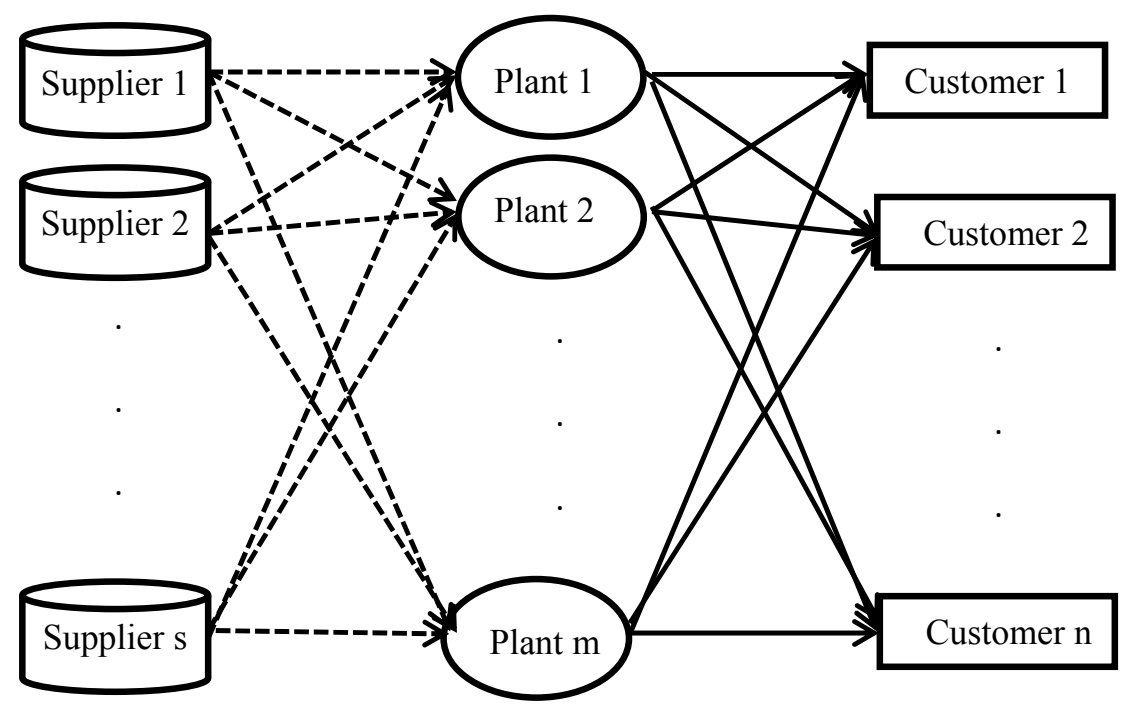

Fig.1. The proposed structure of the supply chain

Supply chain faces make or buy decision and aims at determining whether selecting insourcing suppliers (Make decision) or outsourcing ones (Buy decision). Limited capacities of plant production lines, plant warehouses and supplier warehouses are the other assumptions, which are noticed in this supply chain design. The appropriate selection of suppliers, the optimal amounts of raw materials shipped from the selected suppliers to the plants in each period, the optimal amounts of products produced at each plant in each period, the optimal amounts of products kept at the warehouses in each period, the optimal amounts of product that should be shipped from the plants to the customers in each period and the optimal failure rate of selected suppliers in Make decision (insourcing case) are the decision variables considered in this supply chain.

At the following, all problem parameters and variables are depicted and then the models will be generated. Some parameters and variables which only belong to the one of the decisions (Make or Buy) are depicted in parenthesizes.

$\begin{array}{ll}\text { Notations } & \\ s & \text { The number of potential suppliers } \\ m & \text { The number of plants } \\ n & \text { The number of customers } \\ f & \text { The number of raw materials } \\ \tau & \text { The number of periods } \\ \rho & \text { The number of suppliers which are chosen } \\ i & \text { The supplier index } \\ j & \text { The plant index } \\ k & \text { The customer index } \\ r & \text { The raw material index } \\ t & \text { The period index } \\ C P_{r i t} & \text { Purchasing cost of raw material } r \text { from supplier } i \text { in period } t \text { (in Buy decision) } \\ C P^{\prime} & \text { Production cost of raw material } r \text { forsupplier } i \text { in period } t \text { (in Make decision) } \\ C M_{t} & \text { Production cost in period } t \\ C T S_{i j t} & \text { Transportation cost from supplier } i \text { to plant } j \text { in period } t \\ C T P_{j k t} & \text { Transportation cost from plant } j \text { to customer } k \text { in period } t \\ C H_{t} & \text { Holding cost in period } t \\ S Q C_{r i j t} & i^{t h} \text { supplier quality cost of raw material } r \text { for plant } j \text { in period } t \text { (in Buy decision) }\end{array}$


$C O Q_{\text {rijt }} \quad$ Cost of quality of raw material which is provided by supplier $i$ for plant $j$ in period $t$ (in

$D_{k t} \quad$ The demand of customer $k$ in period $t$

$C A P P_{j} \quad$ The capacity of plant $j$ production line

$C A P S_{i} \quad$ The capacity of supplier $i$

$C A P I_{j} \quad$ The capacity of plant $j$ warehouse

$V_{\text {ol }} \quad$ The volume of raw material $r$

$U_{r} \quad$ The amount of raw material $r$ used in the product

$W_{r} \quad$ The importance of raw material $r$ in the product

$D R_{r i}^{S} \quad$ The defective rate of raw material $r$ of supplier $i$ (in Buy decision)

$\Omega_{t} \quad$ Inspection cost in period $t$ (in Buy decision)

$C Q_{\text {rit }} \quad$ The minimum cost of quality

$\mu \quad$ The rate of cost of quality increment(in Make decision)

$M F \quad$ The acceptable maximum failure rate

Variables

$y_{\text {rijt }} \quad$ The amount of raw material $r$ purchased from supplier $i$ by plant $j$ in period $t$

$x_{j t}^{P} \quad$ The products which are produced in plant $j$ in period $t$

$x_{j k t}^{P C} \quad$ The products shipped from plant $j$ to customer $k$ in period $t$

$I_{j t} \quad$ The inventory level of plant $j$ in period $t$

$z_{i} \quad$ A binary variable that is equal to 1 if supplier $i$ is selected , 0 otherwise

$F R_{r i}^{S} \quad$ The failure rate of raw material $r$ which is provided by supplier $i$ (in Make decision)

An appropriate planning is sought for a two-echelon supply chain, which consists of several suppliers, plants and customers. In this paper, two different cases are defined and modeled by considering SS:MOB, which deals with strategic decisions of making or buying. The results are discussed by offering computational experiments. The two cases are as follows:

1. Case 1 (Buy Decision):

The outsourcing suppliers are chosen for providing all raw materials.

2. Case 2 (Make Decision):

The insourcing suppliers are chosen for providing all raw materials.

\section{Case 1 (Buy Decision)}

In this case, the suppliers are not an integral part of supply chain. The proposed model (1) is formulated as follows:

$$
\begin{aligned}
\min \sum_{r=1}^{f} \sum_{i=1}^{s} \sum_{j=1}^{m} & \sum_{t=1}^{\tau} C P_{\text {rit }} \cdot y_{\text {rijt }}+\sum_{r=1}^{f} \sum_{i=1}^{s} \sum_{j=1}^{m} \sum_{t=1}^{\tau} C T S_{i j t} \cdot y_{\text {rijt }} \\
& +\sum_{j=1}^{m} \sum_{t=1}^{\tau} C M_{t} \cdot x_{j t}^{P} \\
& +\sum_{j=1}^{m} \sum_{k=1}^{n} \sum_{t=1}^{\tau} C T P_{j k t} \cdot x_{j k t}^{P C}+\sum_{j=1}^{m} \sum_{t=1}^{\tau} C H_{t} \cdot I_{j t}+\sum_{r=1}^{f} \sum_{i=1}^{s} \sum_{j=1}^{m} \sum_{t=1}^{\tau} \Omega_{t} \cdot y_{r i j t}
\end{aligned}
$$

subject to

$$
\sum_{j=1}^{m} x_{j k t}^{P C}=D_{k t} \quad \forall k \text { and } t
$$




$$
\begin{array}{ll}
I_{j t}=I_{j t-1}+x_{j t}^{P}-\sum_{k=1}^{n} x_{j k t}^{P C} & \forall j \text { and } t \\
x_{j t}^{P} \leq C A P P_{j} & \forall j \text { and } t \\
I_{j t} \leq C A P I_{j} & \forall j \text { and } t \\
\sum_{r=1}^{f} \sum_{j=1}^{m} V_{o l} \cdot y_{r i j t} \leq C A P S_{i} \cdot z_{i} & \forall i \text { and } t \\
\sum_{j=1}^{m} U_{r} \cdot x_{j t}^{P}=\sum_{i=1}^{s} \sum_{j=1}^{m} y_{r i j t} \cdot\left(1-D R_{r i}^{S}\right) & \forall r \text { and } t \\
\sum_{i=1}^{s} z_{i}=\rho & \\
y_{r i j t}, x_{j t}^{p}, x_{j k t}^{P C}, I_{j t} \geq 0 & \\
z_{i} \in\{0,1\} & \forall r, i, j, k \text { and } t
\end{array}
$$

The objective function minimizes the following costs respectively:

1. The purchasing cost of raw material from suppliers,

2. The shipment cost of raw materials transferred from suppliers to plants,

3. The production cost of products at plants,

4. The shipment cost of products transferred from plants to customers,

5. The inventory cost of products in the plant warehouses at the end of each period,

6. The supplier quality cost.

Supplier quality costs are those costs that the suppliers impose on the supply chain to maintain a desirable quality for raw materials. In fact, the manufacturing plant inspects the incoming raw materials before using them in the production line.

The raw materials are inspected in the plants and good materials are separated from defective ones. The wages of those personnel who spend time on inspecting each raw material in period tis $\Omega_{t}$.

Constraint (2) depicts that all plants are producing enough products to meet customers' demand in each period. Constraint (3) ensures that the inventory level of each plant warehouse in one period equals the amount of products, which are remained from previous periods and the products produced by plants but the amount of products, which are sent to the customers should be subtracted from the existing mentioned inventory. Constraint (4) ensures that plants' production should not exceed their capacities. According to the constraint (5), the inventory level of each plant warehouse should not exceed the maximum capacity of each warehouse. The constraint (6) states that each supplier warehouse with respect to the volume of each raw material has a limited capacity. Constraint (7) insures that the amounts of raw materials used in the production of products in all plants in one period are equal to the percentage of good quality materials supplied by all suppliers. Constraint (8) states that the number of suppliers who are chosen for supplying raw materials is definite and equals $\rho$.

\section{Case 2 (Make Decision)}

Here, the perspective will be that of supply chain as a whole, meaning suppliers are subsidiaries of the supply chain and are an integral part of it; so the production cost and other operational costs at the supplier would also be cost attributes for the supply chain. Therefore, the proposed model in case (2) is as follows: 


$$
\begin{aligned}
\min \sum_{r=1}^{f} \sum_{i=1}^{s} \sum_{j=1}^{m} & \sum_{t=1}^{\tau} C P^{\prime}{ }_{r i t} \cdot y_{r i j t}+\sum_{r=1}^{f} \sum_{i=1}^{s} \sum_{j=1}^{m} \sum_{t=1}^{\tau} C T S_{i j t} \cdot y_{r i j t} \cdot\left(1-F R_{r i}^{S}\right) \\
& +\sum_{\substack{j=1 \\
m}}^{\tau} \sum_{t=1}^{m} C M_{t} \cdot x_{j t}^{P} \\
& +\sum_{j=1}^{m} \sum_{k=1}^{n} \sum_{t=1}^{\tau} C T P_{j k t} \cdot x_{j k t}^{P C} \\
& +\sum_{j=1}^{m} \sum_{t=1}^{\tau} C H_{t} \cdot I_{j t}+\sum_{r=1}^{f} \sum_{i=1}^{s} \sum_{j=1}^{m} \sum_{t=1}^{\tau}\left(C Q_{r i t} \cdot e^{\mu \cdot\left(\frac{1-F R_{r i}^{S}}{F R_{r i}^{S}}\right)}\right) \cdot y_{r i j t}
\end{aligned}
$$

subject to

Eqs. (2), (3), (4), (5), (6) and Eq. (8)

$$
\begin{array}{ll}
\sum_{j=1}^{m} U_{r} \cdot x_{j t}^{P}=\sum_{i=1}^{S} \sum_{j=1}^{m} y_{r i j t} \cdot\left(1-F R_{r i}^{S}\right) & \forall r \text { and } t \\
F R_{r i}^{S} \leq M F & \forall r \text { and } i \\
y_{r i j t}, x_{j t}^{p}, x_{j k t}^{P C}, I_{j t}, F R_{r i}^{S} \geq 0 & \forall r, i, j, k \text { and } t \\
z_{i} \in\{0,1\} & \forall i
\end{array}
$$

As it is observed, the difference between the first and the second models is on their objective function and some of their constraints.

The differences between the objective functions of model (1) and model (2) are as follows: In the Make decision, raw material purchasing cost is replaced by the production cost. The second term in the objective function of case 2 (Make decision) has also changed. In fact, as the suppliers are an integral part of the supply chain, 100 percent inspection happens at the supplier and the good raw materials are only shipped to plants. The last terms in both objective functions differ from each other. COQ which only consists of prevention and appraisal costs are included in the objective function of case 2 (Make decision).

The constraints 7 and 9 differs from constraints 11 and 13, respectively. In constraint $7, F R_{r i}^{S}$ is a variable but $D R_{r i}^{S}$ is a parameter in constraint 11 because the defective rate of raw materials is constant and definite in Buy decision and there is no control in its change but in Make decision, the optimal value of failure rate of raw materials is sought as it is controllable and variable. $F R_{r i}^{S}$ as a variable is also added to constraint 13. The constraint 12 is added to the other constraints existed in case 2 (Make decision) and states that the supplier failure rate should not exceed the acceptable maximum level.

The other constraints in both models are the same.

\section{Numerical example}

This section provides computational experiments to evaluate the performance of the proposed models. At first, a small-sized problem is presented and the optimal solution changes can be observed by solving each proposed model in the two cases. Then some additional problems with different sizes are solved to show the efficiency of the models. The objective function values and the run times spent for solving the problems are depicted. GAMS as an optimization software is used for solving all examples of this section. 
A supply chain has a three manufacturing plants that produces a product, which is composed of three raw materials. These three raw materials are supplied by six potential suppliers of whom only two suppliers are chosen. The manufacturing plants deliver their products to 5 customers. The supply chain aims at obtaining the optimal values of decision variables in a time horizon of three periods. The costs of production, holding and raw material inspection (in Buy decision) in different periods are depicted in Table1.

Table 1

The supply chain costs

\begin{tabular}{cccc}
\hline$t$ & $C M_{t}$ & $C H_{t}$ & $\Omega_{t}$ (in Buy decision) \\
\hline 1 & 40 & 11 & 7 \\
2 & 41 & 12 & 8 \\
3 & 42 & 13 & 9 \\
\hline
\end{tabular}

The volume of each raw material, the amount of their usage in the product and their importance are illustrated in Table 2.

Table 2

Data about raw materials

\begin{tabular}{cccc}
\hline$r$ & $\mathrm{Vol}_{r}$ & $U_{r}$ & $w_{r}$ \\
\hline 1 & 4 & 2 & 0.3 \\
2 & 3 & 1 & 0.3 \\
3 & 2 & 3 & 0.4 \\
\hline
\end{tabular}

All supplier capacities are considered 15000 and the capacities of production lines and plant warehouses are available in Table 3.

Table 3

Plant capacities

\begin{tabular}{ccc}
\hline$j$ & $C A P P_{j}$ & $C A P I_{j}$ \\
\hline 1 & 5920 & 592 \\
2 & 6000 & 600 \\
3 & 6250 & 625 \\
\hline
\end{tabular}

The purchasing costs (in Buy decision) and the production costs (in Make decision) of different raw materials in three time periods are depicted in Table 4 whose rows indicate the three time periods and its columns state the purchasing or production costs.

Table 4

The purchasing costs of different raw material

\begin{tabular}{|c|c|c|c|c|c|c|c|c|c|c|c|c|c|c|c|c|c|c|c|}
\hline & \multicolumn{19}{|c|}{$C P_{\text {rit }} \& C P_{\text {rit }}^{\prime}$} \\
\hline & \multirow[t]{2}{*}{$t$} & \multicolumn{18}{|c|}{$r . i$} \\
\hline & & 1.1 & 1.2 & 1.3 & 1.4 & 1.5 & 1.6 & 2.1 & 2.2 & 2.3 & 2.4 & 2.5 & 2.6 & 3.1 & 3.2 & 3.3 & 3.4 & 3.5 & 3.6 \\
\hline & 1 & 22 & 21 & 19 & 25 & 21 & 21 & 20 & 21 & 23 & 29 & 22 & 21 & 19 & 19 & 21 & 25 & 20 & 22 \\
\hline \multirow[t]{3}{*}{$C P_{\text {rit }}$} & 2 & 23 & 21 & 22 & 26 & 22 & 22 & 21 & 22 & 24 & 30 & 22 & 22 & 19 & 20 & 21 & 26 & 22 & 23 \\
\hline & 3 & 24 & 22 & 22 & 28 & 23 & 23 & 22 & 22 & 24 & 30 & 23 & 24 & 21 & 22 & 22 & 28 & 24 & 23 \\
\hline & 1 & 18 & 19 & 18 & 23 & 19 & 20 & 19 & 19 & 21 & 27 & 21 & 20 & 18 & 18 & 20 & 24 & 19 & 21 \\
\hline \multirow[t]{2}{*}{$C P^{\prime}{ }_{\text {rit }}$} & 2 & 18 & 19 & 20 & 24 & 21 & 21 & 20 & 20 & 21 & 28 & 21 & 20 & 18 & 19 & 20 & 25 & 20 & 21 \\
\hline & 3 & 19 & 20 & 20 & 26 & 22 & 22 & 21 & 20 & 23 & 29 & 22 & 21 & 20 & 19 & 20 & 26 & 23 & 21 \\
\hline
\end{tabular}

In fact, the first number is raw material and the second number is supplier. As it is observed above, the purchasing costs in Buy decision is a little bit higher than production cost in Make decision. The 
transportation costs among different suppliers and the plants and among the plants and the customers in different periods are depicted in Tables 5 and 6, respectively.

Table 5

The shipment costs between the suppliers and the plants

\begin{tabular}{|c|c|c|c|c|c|c|c|c|c|c|c|c|c|c|c|c|c|c|}
\hline \multicolumn{19}{|c|}{$C T S_{i j t}$} \\
\hline$t$ & & & & & & & & & & & & & & & & & & \\
\hline & 1.1 & 1.2 & 1.3 & 2.1 & 2.2 & 2.3 & 3.1 & 3.2 & 3.3 & 4.1 & 4.2 & 4.3 & 5.1 & 5.2 & 5.3 & 6.1 & 6.2 & 6.3 \\
\hline 1 & 10 & 8 & 9 & 10 & 9 & 8 & 9 & 9 & 12 & 11 & 10 & 14 & 12 & 14 & 8 & 14 & 13 & 13 \\
\hline 2 & 11 & 9 & 9 & 11 & 10 & 8 & 10 & 10 & 13 & 11 & 11 & 15 & 13 & 15 & 8 & 14 & 14 & 14 \\
\hline 3 & 11 & 9 & 10 & 11 & 10 & 9 & 10 & 10 & 13 & 12 & 11 & 15 & 13 & 15 & 9 & 15 & 15 & 14 \\
\hline
\end{tabular}

Table 6

The shipment costs between the plants and the customers

\begin{tabular}{cccccccccccccccc}
\hline \multicolumn{10}{c}{$C T P_{j k t}$} \\
$t$ & \multicolumn{10}{c}{ j,k } \\
\hline & 1.1 & 1.2 & 1.3 & 1.4 & 1.5 & 2.1 & 2.2 & 2.3 & 2.4 & 2.5 & 3.1 & 3.2 & 3.3 & 3.4 & 3.5 \\
\hline 1 & 13 & 8 & 8 & 9 & 13 & 8 & 8 & 10 & 9 & 10 & 9 & 11 & 10 & 11 & 10 \\
2 & 13 & 9 & 9 & 11 & 13 & 11 & 10 & 12 & 11 & 10 & 11 & 11 & 11 & 11 & 10 \\
3 & 14 & 10 & 10 & 12 & 14 & 11 & 11 & 12 & 12 & 11 & 12 & 12 & 12 & 12 & 11 \\
\hline
\end{tabular}

The customer demands in different periods are depicted in Table 7. The defective rates of raw material, which are supplied by different suppliers (in Buy decision) are available in Table 8 .

Table 7

Customer demands

\begin{tabular}{|c|c|c|c|}
\hline & & $t$ & \\
\hline$k$ & 1 & 2 & 3 \\
\hline 1 & 380 & 400 & 415 \\
\hline 2 & 200 & 250 & 270 \\
\hline 3 & 320 & 350 & 400 \\
\hline 4 & 330 & 340 & 380 \\
\hline 5 & 350 & 360 & 390 \\
\hline
\end{tabular}

Table 8

The defective rate of raw material (in Buy decision)

\begin{tabular}{cccccccc}
\hline \multicolumn{7}{c}{} & \multicolumn{1}{c}{$i$} \\
\hline$r$ & 1 & 2 & 3 & 4 & 5 & 6 \\
\hline 1 & 0.06 & 0.07 & 0.05 & 0.08 & 0.07 & 0.01 \\
2 & 0.10 & 0.02 & 0.05 & 0.03 & 0.10 & 0.04 \\
3 & 0.03 & 0.04 & 0.04 & 0.04 & 0.10 & 0.03 \\
\hline
\end{tabular}

The maximum acceptable level of failure rate is 0.3 and the minimum suppliers' cost of quality which is occurred in 100 percent failure rate (in make-decision) is illustrated in Table 9. The rate of cost of quality increment is 0.05 .

Table 9

The minimum suppliers' cost of quality (in Make decision)

\begin{tabular}{ccccccccccccccccccc}
\hline \multicolumn{11}{c}{$C Q_{\text {rit }}$} \\
\multicolumn{11}{c|}{ r.i } \\
\hline & 1.1 & 1.2 & 1.3 & 1.4 & 1.5 & 1.6 & 2.1 & 2.2 & 2.3 & 2.4 & 2.5 & 2.6 & 3.1 & 3.2 & 3.3 & 3.4 & 3.5 & 3.6 \\
\hline 1 & 4 & 3 & 3 & 3 & 3 & 3 & 1 & 4 & 2 & 3 & 2 & 1 & 3 & 2 & 1 & 2 & 4 & 1 \\
2 & 4 & 3 & 3 & 4 & 3 & 3 & 2 & 4 & 2 & 3 & 2 & 1 & 3 & 2 & 1 & 2 & 4 & 1 \\
3 & 5 & 3 & 3 & 4 & 4 & 4 & 2 & 4 & 2 & 3 & 2 & 1 & 3 & 3 & 2 & 3 & 4 & 2 \\
\hline
\end{tabular}


The results obtained by solving the first and second models are totally different from each other. The optimal objective function value which obtained by solving model in case 1 (Buy decision) is $\underline{1511245}$ and in this case the suppliers 2 and 6 are also chosen. The optimal objective function value obtained by solving the model in case 2 (Make decision) is 1505253 and the suppliers 2 and 3 are selected. The optimal values of failure rate of raw materials for selected insourcing suppliers are depicted at Table 10.

Table 10

The failure rate of raw material (in Make-decision)

\begin{tabular}{ccc}
\hline & $i$ & 3 \\
\hline$r$ & 2 & 0.031 \\
\\
\hline 1 & 0.031 & 0.029 \\
3 & 0.036 & 0.029 \\
\hline
\end{tabular}

As it is observed, selecting suppliers 2 and 3 in Make decision model have imposed lower costs than selecting suppliers 2 and 6 in buy-decision on supply chain. Prevention and appraisal costs should be afforded by suppliers 2 and 3 in order to change the failure rate of raw materials existed in Table 8 into the values existed Table 10 and therefore the cost associated with insourcing suppliers will be lower than the costs in outsourcing case. If it is assumed that the failure rate of raw materials, which are provided by insourcing suppliers (Make decision) is the same as definite values in outsourcing case (Buy decision) and becomes a constant value, the optimal cost in make-decision will be 4592466, which are three times as much as the implementation of buy-decision model. Therefore, if buy-decision is selected as an optimal case (in regard to proposed example), prevention and appraisal costs should be considered in order to achieve the failure rate of raw material in Table 10.

To show the efficiency of the models, twelve problems with different sizes are solved and the objective function values, the selection of optimal case, the run times spent for solving the problems are recorded in Table 11. In these problems the number of raw materials, number of potential and chosen suppliers, number of plants, number of customers and number of periods are varied. The required parameters are extracted from the following uniform distributions:

$C M_{t} \approx \mathrm{U}(40,45), C H_{t} \approx \mathrm{U}(10,15), \Omega_{t} \approx \mathrm{U}(5,10), \operatorname{Vol}_{r} \approx \mathrm{U}(1,5), U_{r} \approx \mathrm{U}(1,3), W_{r} \approx \mathrm{U}(0.1,0.9), C A P S_{i} \approx$ $\mathrm{U}(10000,15000), C A P P_{j} \approx \mathrm{U}(5500,6500), C A P I_{j} \approx \mathrm{U}(550,650), C P_{\text {rit }} \approx \mathrm{U}(15,30), C P^{\prime}{ }_{r i t} \approx \mathrm{U}(18,33)$, $C T S_{i j t} \approx \mathrm{U}(8,16), C T P_{j k t} \approx \mathrm{U}(8,16), D_{k} \approx \mathrm{U}(200,500), D R_{r i}^{S} \approx \mathrm{U}(0.01,0.1), C Q_{r i t} \approx \mathrm{U}(1,5), M F \approx$ $\mathrm{U}(0.3,0.4), \mu \approx \mathrm{U}(0.05,0.06)$

\section{Table 11}

Results for the different problem size

\begin{tabular}{|c|c|c|c|c|c|c|c|c|c|c|}
\hline \multirow[b]{2}{*}{ No. } & \multirow[b]{2}{*}{$s(\rho)$} & \multirow[b]{2}{*}{$m$} & \multirow[b]{2}{*}{$N$} & \multirow[b]{2}{*}{$\tau$} & \multirow[b]{2}{*}{$f$} & \multicolumn{2}{|c|}{ Case 1 (outsourcing) } & \multicolumn{2}{|c|}{ Case 2 (insourcing) } & \multirow[b]{2}{*}{ Optimal case } \\
\hline & & & & & & $\begin{array}{l}\text { Objective } \\
\text { value }\end{array}$ & $\begin{array}{l}\text { CPU time } \\
\text { (second) }\end{array}$ & $\begin{array}{c}\text { Objective } \\
\text { value }\end{array}$ & $\begin{array}{l}\text { CPU time } \\
\text { (second) }\end{array}$ & \\
\hline 1 & $2(1)$ & 2 & 2 & 1 & 2 & $7.46 \times 10^{5}$ & 0.89 & $7.66 \times 10^{5}$ & 1.74 & Buy \\
\hline 2 & $2(1)$ & 4 & 5 & 3 & 4 & $1.22 \times 10^{6}$ & 1.61 & $1.21 \times 10^{6}$ & 34.54 & Make \\
\hline 3 & $2(1)$ & 6 & 8 & 5 & 6 & $2.72 \times 10^{6}$ & 2.31 & $2.75 \times 10^{6}$ & 161.62 & Buy \\
\hline 4 & $5(2)$ & 4 & 5 & 1 & 2 & $1.30 \times 10^{6}$ & 1.65 & $1.27 \times 10^{6}$ & 6.58 & Make \\
\hline 5 & $5(2)$ & 6 & 8 & 3 & 4 & $2.21 \times 10^{6}$ & 2.36 & $2.19 \times 10^{6}$ & 83.11 & Make \\
\hline 6 & $5(2)$ & 8 & 11 & 5 & 6 & $2.98 \times 10^{6}$ & 3.07 & $2.95 \times 10^{6}$ & 315.39 & Make \\
\hline 7 & $10(4)$ & 6 & 8 & 1 & 2 & $1.91 \times 10^{7}$ & 2.73 & $1.92 \times 10^{7}$ & 22.98 & Buy \\
\hline 8 & $10(4)$ & 8 & 11 & 3 & 4 & $2.84 \times 10^{7}$ & 3.44 & $2.82 \times 10^{7}$ & 186.63 & Make \\
\hline 9 & $10(4)$ & 10 & 14 & 5 & 6 & $3.49 \times 10^{7}$ & 4.17 & $3.55 \times 10^{7}$ & 610.94 & Buy \\
\hline 10 & $20(8)$ & 8 & 11 & 1 & 2 & $2.83 \times 10^{8}$ & 4.63 & $2.78 \times 10^{8}$ & 49.57 & Make \\
\hline 11 & $20(8)$ & 12 & 14 & 3 & 4 & $3.87 \times 10^{8}$ & 5.52 & $3.93 \times 10^{8}$ & 473.73 & Buy \\
\hline 12 & $20(8)$ & 14 & 17 & 5 & 6 & $4.69 \times 10^{8}$ & 6.23 & $4.68 \times 10^{8}$ & 1404.41 & Make \\
\hline
\end{tabular}


As it is observed, case 1 (buy-decision) which is a Mixed Integer Programming (MIP) solves the problems faster compared with case 2 (make-decision) since the second model is formulated as a Mixed Integer Non-linear programming (MINLP). The exact solution method (via optimization solver) used in this paper is appropriate for small and medium sized problems (it is depicted in Table 11). One of make or buy decisions can be chosen as an optimal strategy of supply chain by considering random values in each problem and it is not predicted, previously.

\section{Conclusion}

In this paper, two different cases that follow different strategic decisions have been proposed in a two-echelon supply chain design and supplier selection. A special model is separately formulated for each case. The difference among the models is in their supply strategy of supply chain. The first case deals with outsourcing supply (Buy decision) and the objective functions and constraints are

formulated by considering this strategic decision. In this case, the suppliers are not an integral part of supply chain. The other case is insourcing suppliers (Make decision) which are an integral part of supply chain. In this paper SS:MOB is in detail discussed and some numerical examples have been presented and finally it depicts that which strategy (Make buy) is going to follow cost minimization which is the goal of each supply chain.

Considering quality function as the second objective function or uncertainty in customer demands can be interesting topics for future researches.

\section{References}

Agarwal, P., Sahai, M., Mishra, V., Bag, M., \& Singh, V. (2011). A review of multi-criteria decision making techniques for supplier evaluation and selection. International Journal of Industrial Engineering Computations, 2, 801-810.

Heikkilä, J. (2002). From supply to demand chain management: efficiency and customer satisfaction. Journal of Operations Management, 20(6), 747-767.

Jamshidi, B., \& Ismaeli, S., (2012). Analyzing effective elements in agile supply chain. Management Science Letters, 2, 369-378

Mandy, D. M. (2009).Pricing inputs to induce efficient Make-or-Buy decisions. Journal of Regulatory Economics, 36(1), 29-43.

Moschuris, S. J. (2008). Organizational participants in the make-or-buy process. Industrial Marketing Management, 37(2), 143-153.

Moses, A., \& Åhlström, P. (2008). Dimensions of change in make or buy decision processes. Strategic Outsourcing. An International Journal, 1(3), 230-251.

Rabinson, C. J., \& Malhotra, M. K. (2005). Defining the concept of supply chain quality management and its relevance to academic and industrial practice. International Journal of Production Economics, 96(3), 315-337.

Srivastava S.K. (2008). Towards estimating Cost of Quality in supply chains. Total Quality Management 19, 193-208.

Williamson, O. E. (2008). Outsourcing: Transaction cost economics and supply chain management. Journal of Supply Chain Management, 44(2), 5-16.

Yazdian, S. A., \& Shahanaghi, K. (2011). A multi-objective possibilistic programming approach for locating distribution centers and allocating customers demands in supply chains. International Journal of Industrial Engineering Computations, 2, 193-202. 